\title{
A Little Bit of That from One of Your Grandparents: Interpreting Others' Direct-to-Consumer Genetic Ancestry Results
}

\author{
Piotr S. Bobkowski ${ }^{\circledR}$, John C. Watson * and Olushola O. Aromona \\ William Allen White School of Journalism and Mass Communications, University of Kansas, Lawrence, \\ KS 766045, USA; bobkowski@ku.edu (P.S.B.); shola.aromona@ku.edu (O.O.A.) \\ * Correspondence: johnwatson@ku.edu
}

Received: 3 April 2020; Accepted: 23 April 2020; Published: 30 April 2020

\begin{abstract}
With more than 25 million tests sold by early 2019, direct-to-consumer genetic ancestry tests expose the public to critical issues of genetics, ancestry, and identity. This study examines how individuals understand the results of a genetic ancestry test. Twenty undergraduate students viewed and interpreted an unfamiliar individual's ancestry results. In in-depth interviews, students indicated that the results were easy to read and understand, but that they had difficulty articulating the meaning of the ancestry groups presented in the results. Participants could not accurately paraphrase the test's scientific explanation. Those who engaged with the scientific explanation developed doubts about the test's credibility. There was little consensus about the legitimacy of identity claims from low-proportion ancestry groups. Some students reserved judgment while others identified specific thresholds for what ancestry proportions legitimize identity claims. Results contribute to the literature on the public's understanding of ancestry, genetics, and data interpretation.
\end{abstract}

Keywords: ancestry; data interpretation; direct-to-consumer genetic tests; genetic literacy

\section{Introduction}

In October 2018, four months before declaring her candidacy for President of the United States, Senator Elizabeth Warren released her genetic ancestry test results, which showed that she had a Native American ancestor between six and ten generations ago, making her between $0.02 \%$ and $0.001 \%$ Native American (Linskey 2018). While Warren claimed that the test supported her self-identification as part-Native American, her attempt to prove her family lore backfired. Warren was ridiculed for having miniscule Native American ancestry, and thus for failing to justify employment records that identified her as Native American (Post Editorial Board 2018). Leaders of the Cherokee Nation publicly denounced Warren's claim, asserting that tribes determine tribal citizenship based on culture and history, not on genetic tests. Warren eventually apologized for publicizing her ancestry results (Wade 2019). In a May 2019 poll, 19\% of Democratic voters and 34\% of independent voters said that Warren's handling of her ancestry results diminished her favorability as a politician (Zhou 2019).

Understanding public response to the genetic ancestry results of newsmakers such as Warren can benefit from a better conceptualization of how individuals process and understand ancestry test results and the knowledge structures that inform these interpretations. As of early 2019, more than 25 million direct-to-consumer genetic ancestry tests had been sold, with sales doubling in both 2017 and 2018, and the companies Ancestry and 23andMe dominating the market (Regalado 2019). Other companies in this space include, FamilyTree DNA, MyHeritage, AfricanAncestry.com, Living DNA, WeGene, and 23 Mofang (Weise 2018). Given the tests' widespread use, future public controversies related to genetic ancestry results seem inevitable. Thus far, genetic ancestry research has documented how these tests are 
marketed (Roth and Ivemark 2018), test takers' motivations and demographic characteristics (Horowitz et al. 2019; Wagner and Weiss 2012), and how individuals integrate ancestry results and their identities (Shim et al. 2018). The process that individuals use to interpret ancestry results, particularly those that do not belong to them, has not been examined in detail. This study focuses on autosomal DNA tests, that is, tests that examine DNA markers contained in autosomal chromosomes, as opposed to tests that examine DNA contained in the Y-chromosome (y-DNA tests) or mitochondria (mDNA tests). Using the framework of bottom-up/top-down processing (Dunlop and Fetzer 1993), and a sample of U.S. university students, this study begins to explain how individuals interpret ancestry test results and how they determine whether an ancestry legitimizes one's identity. More broadly, the study contributes to the literature on the public's understanding of ancestry and genetics.

\section{Literature Review}

\subsection{Interpreting Direct-to-Consumer Genetic Tests}

Members of the public did not interpret genetic test results without professional guidance before 2007, when direct-to-consumer genetic tests debuted (Felzmann 2015; Ostergren et al. 2015). Prior to this, physicians, genetic counselors, or genetic lab specialists explained test results to their patients and clients in medical, criminal justice, and legal settings (Juengst 2004a, 2004b; Quaid 2004). Today, consumers can bypass professional interpreters when ordering tests on a range of genetic factors including ancestry, predisposition to disease, and athletic dispositions (Felzmann 2015). The absence of professionals interpreting direct-to-consumer genetic tests has been a concern in medical contexts, where result misinterpretation can lead to misguided decision-making (Gabel 2012). Some, however, have argued that these fears are overstated (Felzmann 2015; Schleckser 2013). Although direct-to-consumer genetic tests may be viewed as low-consequence recreational activities (Felzmann 2015), knowing how they are interpreted can inform an understanding of genetic test literacy and its cultural consequences.

\subsection{How Genetic Tests and Results Work}

Errors in ancestry result interpretation can stem from a discrepancy between the lay understanding of the test and the scientific analysis that generates genetic ancestry results. The direct-to-consumer test and its online results appear intuitive. A test-taker registers online, submits a saliva sample, and logs back in after a few weeks to read their results (Rutherford 2018). The results show a list of ancestry groups, percentages indicating what proportions of the test-taker's DNA match each group, and a color-coded map illustrating countries and regions associated with the ancestry groups.

This simple process of taking the test and reading its results masks the complex analysis that genetic testing companies perform (Rutherford 2018). Ancestry testing companies maintain lists of ancestry information markers (AIMs) that vary between populations and individuals and are based on previous test-takers' AIMs. 23andMe, for instance, has a database of 45 distinct reference populations, which represent regions, countries, and ethnic groups. A new test-taker may be added to this reference database if they report that all four of their grandparents were born into one reference population, and if their close relatives are not already in the database (23andMe 2019). When a new consumer submits their DNA test, the testing company matches the test taker's AIMs with the AIMs of its reference populations (Roth and Ivemark 2018). It then generates the test taker's results consisting of ancestry groups and their proportions, based on how many AIMs of the test taker's DNA match the company's reference populations (Roth and Ivemark 2018). Testing companies use a default 50\% confidence interval when identifying matches with their reference populations. A test-taker's AIMs that do not match a company's reference populations are reported as an "unassigned" category (23andMe 2019).

Genetic ancestry testing companies have been criticized for misleading customers, lacking transparency, and omitting information about their tests' limitations (Bolnick et al. 2007; Jobling et al. 2016; Lewis et al. 2011; Nordgren and Juengst 2009; Royal et al. 2010; Rutherford 2018). 
Scholars argue that test-takers are led to believe that the tests can provide information about social groups, but in reality the tests reveal very little about race, ethnicity, and tribal status (Bolnick et al. 2007; Royal et al. 2010; Rutherford 2018). The tests also tend to ignore ethnic heterogeneity by grouping neighboring ethnicities in a singular reference category (Royal et al. 2010). Moreover, testing companies' reference populations represent modern-day populations, meaning that they show with whom a test-taker has common ancestry today but not necessarily in the past (Rutherford 2018). Because of migration, time period is important to consider when interpreting ancestry test results. A test-taker may share an ancestry with someone in the current reference population for France, but that same match's great-grandparents may have been born elsewhere, and migrated to France from there. The number of ancestors and the spread of where they were born increases with each generation, potentially providing false leads in the test results (Bolnick et al. 2007). Results are further limited by the size and representativeness of the test companies' reference databases (Felzmann 2015; Horowitz et al. 2019; Royal et al. 2010; Rutherford 2018). Even more problematic, more educated individuals and black and white Americans can be overrepresented in reference populations because they are more likely to take ancestry tests than other subpopulations (Horowitz et al. 2019). Native Americans, conversely, are underrepresented because they tend to distrust population and genetic research (Rutherford 2018; Shah et al. 2010). Understanding how individuals interpret genetic ancestry results can further identify the gulf between what the results actually show and how they are understood.

\subsection{Genetic Ancestry Research}

Research has documented how genetic ancestry tests are marketed, the characteristics and motivations of typical test-takers, and how test-takers react to their own results. Most consumers learn about direct-to-consumer genetic testing from television, radio, and the Internet (Agurs-Collins et al. 2015). Aggressive marketing has contributed to the tests' popularity, with ad campaigns promoting greater identity awareness (Roth and Ivemark 2018), self-knowledge (Nordgren and Juengst 2009), biological kinship (Scodari 2017), and increased lifespans (Borry et al. 2013). Curiosity and a desire to be educated and entertained motivate consumers to purchase the tests (Wagner and Weiss 2012). Research suggests that "later-generation residents of long-standing immigrant receiving countries" are most likely to be test-takers since they have greater uncertainty about their ancestry than more recent immigrants (in Horowitz et al. 2019, p. 166). In the United States specifically, individuals who are older and more educated, and who identify as third- or later-generation Americans, are more likely than other population segments to be interested in genetic ancestry testing.

Studies also have examined what test-takers do with their own newfound ancestry knowledge. Ancestry results tend to elicit positive emotions, pride, and narratives of community attachment among racial and ethnic minorities (Nelson 2008; Shim et al. 2018). Some test-takers use the results as proof of their identities (Nelson and Hwang 2013; Shim et al. 2018). Others re-create their identities in light of the results by, for instance, reconsidering what race they select on the census (Foeman et al. 2015; Lee 2013). Still others do not equate ancestry results with their identities and instead weave the test-derived information into previous personal and family narratives (Foeman et al. 2015; Nelson 2008; Scully et al. 2016; Shim et al. 2018).

In all, despite knowing about who purchases genetic ancestry tests and why, and how they react to their own results, studies have not focused on how individuals process test results, particularly ones from which they are detached, and what shapes their interpretations. We turn next to considering some of these factors.

\subsection{Bottom-Up and Top-Down Processing of Genetic Ancestry Results}

The bottom-up/top-down conceptualization of information processing (Dunlop and Fetzer 1993; Norman and Rumelhart 1975) can be used as a framework for understanding how individuals interpret genetic ancestry results. Bottom-up processing is guided by input received from a stimulus (e.g., data table, map, etc.). Top-down processing is guided by information stored in memory, 
such as domain-specific knowledge. Bottom-up and top-down processes occur simultaneously and in concert with one another (Lewandowsky and Behrens 1999; Shah and Freedman 2011; Shah et al. 2005), and have been used to understand readers' attention to news and advertising stimuli (Bucher and Schumacher 2006; Kruikemeier et al. 2018; Pieters and Wedel 2007).

Bottom-up, stimulus-based processing of ancestry results may include being able to identify the specified ancestry groups, understand group proportions, and match the groups to regions on the accompanying map. The complexity of data presented in a stimulus, such as the number of data points presented, influence the ease and accuracy of interpretation (Meyer et al. 1997; Shah et al. 2005). Results containing more ancestry groups, for instance, may lead to less accurate interpretations than results with fewer groups. Conversely, the color coding of data may increase individuals' perception that the data is easy to interpret (Casali and Gaylin 1988).

Actual and perceived knowledge of science, data, and maps likely influence ancestry result interpretations. Many individuals in the United States may lack the scientific knowledge necessary to interpret ancestry results accurately because, on average, the U.S. public scores poorly on foundational scientific concepts (Downs et al. 2008; Lorenzoni and Pidgeon 2006; Miller 2004; National Science Board NSB). Greater numeracy and, more specifically, understanding of probabilities are related to better comprehension of genetic results (Ostergren et al. 2015; Rutherford 2018), but American adults tend to lag behind in both domains (National Science Board NSB; Stephens et al. 2015). Because a map accompanies ancestry results, the ability to identify locations on a map also may influence interpretations. U.S. college students, however, tend to perform poorly on tests of place location knowledge (Cross 1987; Council on Foreign Relations and National Geographic 2016). In addition to objective knowledge, individuals' perceptions of their math abilities (i.e., math self-efficacy) are associated with better understanding of statistical information (Silk and Parrott 2014). Individuals with self-efficacy for reading maps likewise may view the map as a helpful tool for understanding ancestry results.

Genetic literacy and previous experiences with genetic tests also can influence result interpretations. Americans tend to be familiar with some genetic terms like "gene" and "heredity," but struggle to explain how genes are transferred, where they are located, and how they work (Christensen et al. 2010; Pearson and Liu-Thompkins 2012). Genetic literacy may be related inversely to age, but related positively to socioeconomics (Molster et al. 2009), and shaped by personal and social experience with genetics (Christensen et al. 2010; Molster et al. 2009). Those who have first- or second-hand experience with genetic tests tend to have a more sophisticated understanding of these tests than those with no test experience (Foeman et al. 2015; Nelson and Hwang 2013; Panofsky and Donovan 2019; Scully et al. 2016; Shim et al. 2018).

Understanding how genetic ancestry relates to identity, and what legitimizes membership of an ancestry group, also can shape the interpretation of results. The public reaction to Elizabeth Warren's genetic results highlighted a cultural disagreement over legitimate ancestry-based identity. A genetic ancestry test is a recreational activity for many (Felzmann 2015), so the legitimacy of an ancestry-based identity may also be of little consequence. For others, the genetic test represents higher stakes (Scully et al. 2016), and can even be considered a political act (Brodwin 2002). It is not uncommon that individuals' claims to racial and ethnic group membership are rhetorically and socially scrutinized and challenged (Brubaker 2016). Prior research has examined the extent to which test-takers view their own results as valid (Foeman et al. 2015; Nelson 2008; Nelson and Hwang 2013; Scully et al. 2016; Shim et al. 2018), but studies have not addressed perceptions of the legitimacy of others' ancestry-based identities.

\subsection{Research Questions}

The market popularity of genetic ancestry tests and their potential to shape politics and culture, combined with consumers' autonomy to interpret these results despite their general deficits in science literacy, numeracy, map literacy, and genetic literacy, suggest a need to better understand how individuals interpret these results. Accordingly, this study addresses the following research questions: 
RQ1: How do individuals interpret genetic ancestry results?

RQ2: How does understanding a genetic test's scientific explanation shape result interpretations? RQ3: How do individuals determine whether genetic ancestry results support identity claims?

\section{Materials and Methods}

\subsection{Participants}

Twenty students at the University of Kansas participated in face-to-face, semi-structured in-depth interviews about their interpretations of genetic ancestry test results. After IRB approval, students volunteered to participate having learned about the study in their journalism courses. The exploratory nature of this study justified convenience sampling of college students. Previous studies of genetic ancestry tests relied on convenience student samples (Foeman et al. 2015; Vayena et al. 2014). A college-educated sample also reflects a population more likely to purchase a genetic ancestry test (Agurs-Collins et al. 2015; Horowitz et al. 2019; Ostergren et al. 2015).

Each participant received a $\$ 10$ Amazon gift card in compensation. The research team stopped adding participants to the sample when saturation was reached ( $\mathrm{O}^{\prime}$ reilly and Parker 2013), that is, when team members agreed that new interviews were no longer yielding unique information. See Table 1 for a list of participant pseudonyms and genders.

Table 1. Participant pseudonyms, genders, and questionnaire results.

\begin{tabular}{cccc}
\hline Name & Gender & $\begin{array}{c}\text { Map Literacy Score } \\
\text { (Out of 12) }\end{array}$ & $\begin{array}{c}\text { Experience with } \\
\text { Genetic Ancestry Test }\end{array}$ \\
\hline Jessica & $\mathrm{F}$ & 11 & Maybe \\
Nicole & $\mathrm{F}$ & 9 & No \\
Matthew & $\mathrm{M}$ & 10 & Yes \\
Rachel & $\mathrm{F}$ & 10 & Yes \\
Allison & $\mathrm{F}$ & 12 & Yes \\
Olivia & $\mathrm{F}$ & 10 & Yes \\
Emily & $\mathrm{F}$ & 6 & No \\
Ashley & $\mathrm{F}$ & 7 & No \\
Elizabeth & $\mathrm{F}$ & 8 & Yes \\
Jacob & $\mathrm{M}$ & 7 & Yes \\
Mary & $\mathrm{F}$ & 10 & Yes \\
Brian & $\mathrm{M}$ & 7 & Maybe \\
Laura & $\mathrm{F}$ & 10 & Yes \\
Christina & $\mathrm{F}$ & 10 & Yes \\
Jack & $\mathrm{M}$ & 12 & Yes \\
Amy & $\mathrm{F}$ & 10 & No \\
Katherine & $\mathrm{F}$ & 8 & No \\
Stephanie & $\mathrm{F}$ & 5 & Yes \\
Andrea & $\mathrm{F}$ & 12 & Yes \\
Andrew & $\mathrm{M}$ & 12 & No \\
& $\mathrm{F}$ & Yes $=12$ \\
Total/average & $\mathrm{F}=6$ & No $=6$ \\
& $\mathrm{M}=5$ & 9.3 & Maybe $=2$ \\
\hline
\end{tabular}

\subsection{Stimulus Materials}

Participants' interpretations of genetic ancestry test results were elicited by showing them a printout of results belonging to an individual named Sam Wilder, and asking questions about these results. Results were designed to resemble a 23andMe results layout, with ancestry groups and percentages listed on the left side of the page, and a color-coded map located on the right (see Figure 1). This study aimed to simulate and understand interpretations of third-party results, so in contrast to 
prior research (e.g., Shim et al. 2018), participants were not asked to interpret their own results. At the end of each interview, participants were informed that the test-taker and the results were fictitious.

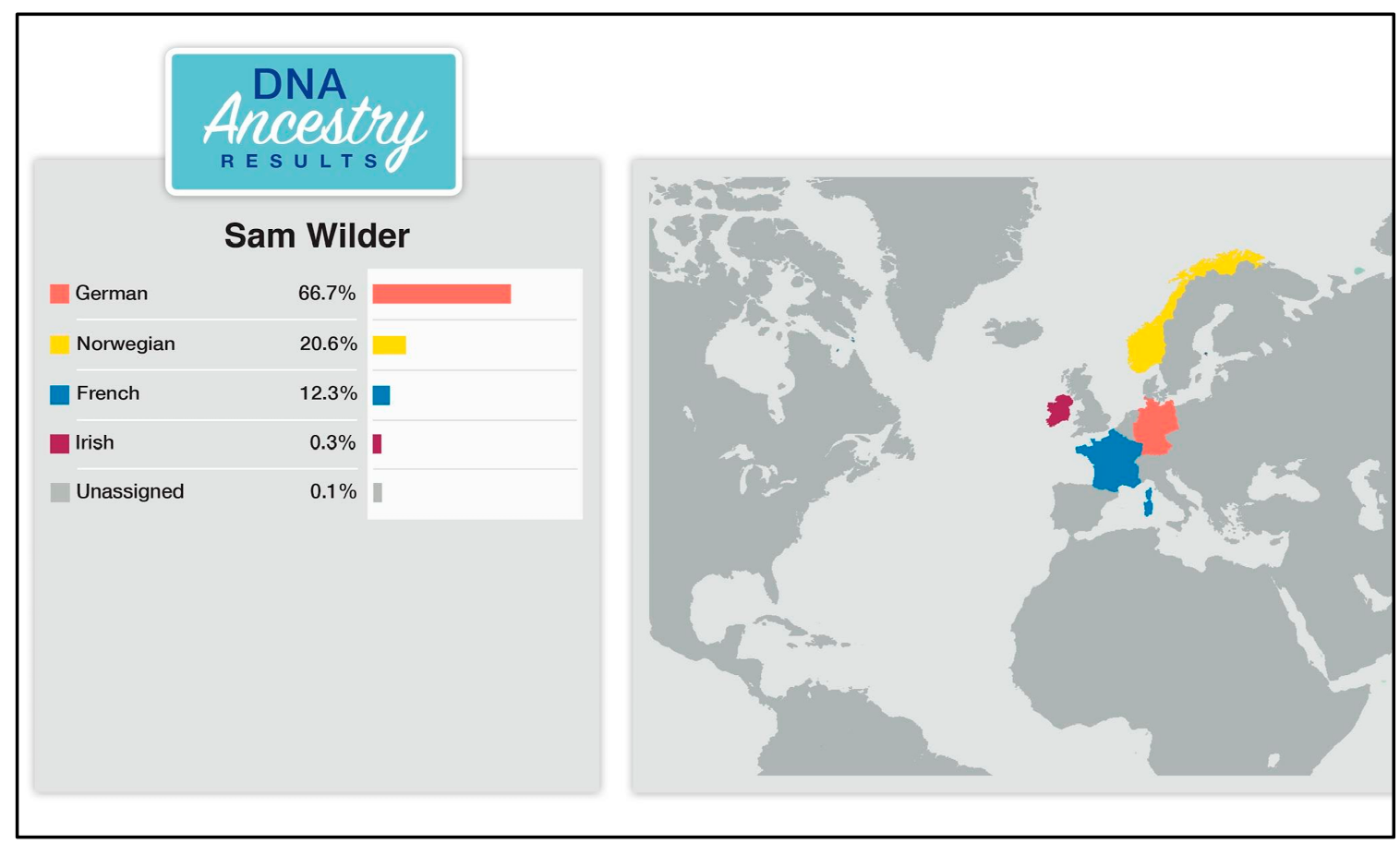

Figure 1. Example of the ancestry results printout that participants viewed and discussed in the interviews.

To gauge whether the complexity of the results shaped interpretations, three versions of the stimulus were rotated among the participants. Shah et al. (1999) similarly used participants' open-ended responses to several stimuli to test the effect of data complexity on interpretation. The stimuli contained either four national ancestry groups, nine national ancestry groups, or six regional ancestry groups. Each list also included an "unassigned" category. Figure 1 presents the four-group stimulus. Information about who viewed which stimulus was included in the analysis.

The questions that participants answered about the stimulus are listed in Appendix A. Interviewers omitted some questions based on participants' prior responses, and asked follow-up questions as necessary to clarify responses, provide examples, and add depth (Rubin and Rubin 2012). Toward the end of each interview, participants read a 140-word scientific explanation of the results, which, at the time of the study, 23andMe linked to from the results page. The explanation was written at a ninth-grade reading level and characterized as "fairly difficult to read," according to a readabilityformulas.com analysis, which integrates eight readability formulas.

\subsection{Questionnaire}

To gauge whether domain knowledge shaped interpretations, map literacy was measured by asking participants to identify six countries on a world map and six states on a U.S. map (Winship 2004). These questionnaire results were integrated in the analysis by categorizing respondents as below-, above-, or average on the map literacy measures. Participants were also asked about their prior test experience, and by examining questionnaire responses within categories for patterns of similarities and differences. See Table 1 for participants' questionnaire results.

\subsection{Analysis}

Interviews were audio-recorded and transcribed. The research team used a thematic analysis approach, which consisted of identifying "what is common to the way a topic is talked or written about and of making sense of those commonalities" (in Braun and Clarke 2012, p. 57). A six-phase 
analysis approach by Braun and Clarke (2012) was followed. In the first phase, each research team member became familiar with the transcribed data, and identified content that may be relevant to the study. Next, each member generated initial codes, aiming to identify latent meanings in the data. The research team then reviewed the coded data together, and began to identify themes. A theme "captures something important about the data in relation to the research question, and represents some level of patterned response or meaning" (in Braun and Clarke 2006, p. 82). Seven initial themes were identified. In the next phase, the team reviewed the themes ensuring that each theme had a single focus in relation to a research question. This led to re-organizing the seven initial themes into those presented next.

\section{Results}

\subsection{Superficial Interpretations}

\subsubsection{Formatting Simplicity}

Nearly all participants said that the genetic ancestry results were easy to interpret. Using bottom-up processing from the results page, many participants used words like "simple," "pretty easy," and "straightforward," to characterize the ancestry groups, group percentages, and associated geographical regions. Although the complexity of the stimulus varied, those who viewed results consisting of more ancestry groups did not express more interpretation difficulties than those who viewed fewer groups.

Most participants said that the map aided their interpretations. Several said that the color coding linking the ancestry groups to corresponding map regions made the results easy to interpret. One participant emphasized the utility of both the map and the color coding:

I think [interpreting the results] was pretty simple, especially with the map right there. Like, even if you didn't know where these countries were originally on the map, it is right there, and so you can just look at the map and it will tell you. And plus, it's color coded, so that really helps a lot, too. (Stephanie)

Simultaneous to praising the color-coded map as a useful interpretation tool, several participants admitted limited geographic knowledge. One participant, for instance, expressed low self-efficacy in geography as she debated the definition of Eastern Europe: "I'm seeing the majority of [this person's ancestry] is coming from Eastern Europe, which-I should have studied my geography before this-is most likely Spain? ... No, that's on the other side, isn't it?" (Jessica). Another participant correctly pointed to Iceland but doubted himself: “I can't tell if that's Iceland or not. I don't know my geography very well" (Matthew). In fact, half of the participants who voiced reservations about their map literacy scored above-average on the map identification task. In general, the color-coded map appeared to assuage participants' doubts in their map-reading skills and increased their confidence in interpreting the results.

\subsubsection{Content Simplicity}

The stimulus design choice to show an all-European ancestry combination contributed to the participants perceiving the results as easy to interpret. Participants constructed stereotypical mental images of the test taker's physical features based on the ancestry results. One participant said that using the ancestry group percentages, "you can kind of assume what he may or may not look like, bone structure, et cetera" (Elizabeth). Participants said that had the results depicted a mixed-race individual, one whose mental image was more challenging to construct, the results would have been harder to interpret. One participant, for instance, said:

I think that these results are pretty plain ... If it had been, like, Western European and, like, Northern African, I'd have been, like, "Oh, that's interesting." But this is all, like, the same general region. (Laura) 
Some participants said that the results were easy to interpret because they looked like their own or a relative's results. Twelve of the 20 participants either had taken the test themselves or had a close family member take it. One participant, for instance, said that the European ancestry results were "common," and looked "kind of how" her ancestry results looked.

In all, participants thought the results were intuitive and easy to interpret. They attributed the simplicity of the results to the results' clear and helpful formatting, and to an illustration that helped them overcome perceived deficiency in map knowledge. In the absence of information about the test-taker, participants leaned on stereotypes to generate mental images and interpretations.

\subsubsection{Unclear Meaning}

Participants' responses became less certain when explaining the meaning of the ancestry groups. To formulate their answers, participants shifted from stimulus-based, bottom-up interpretations to drawing on their genetic knowledge, map knowledge, and test experiences. Several participants said simply that they didn't know or weren't sure what the ancestry groups meant. Some participants connected their understanding of "percent" with what the ancestry test measured. Asked what "20.6\% Norwegian" meant, for instance, one participant said:

That's the part I'm confused about. I don't know what that means.... I don't know, it's hard to trace that. Like, are $20.6 \%$ of his ancestors were Norwegian? Or is he alone $20.6 \%$ ? (Ashley)

Another participant, asked what it meant to be "66.7\% English and Welsh," followed similar reasoning:

If it's, like, the amount of family members he's had? ... I'd think that it's just out of all of his ancestors, 66.7, maybe, that percent of his past family, maybe, was born in that country. (Nicole)

While participants' uncertainty was consistent, ancestry groups with larger percentages appeared more challenging to interpret than small ones, perhaps because smaller proportions were easier to dismiss as insignificant.

Participants conceptualized ancestry groups using two basic concepts: grandparents and migration. The concept of grandparents came up in relation to smaller ancestry proportions, which generated less interpretive work. Asked what it meant to be "2.1\% Belgian," for instance, one participant said that one of the test-taker's grandparents must have been "a little bit Belgian" (Katherine). Another participant, asked to explain what it meant to be " $4.2 \%$ Irish," said, " ... you probably have a little bit of that from one of your grandparents" (Olivia).

A separate group of participants used the concept of migration to explain ancestry group combinations. All of these participants scored above average on the map identification task. Greater geographical awareness, therefore, seemed to trigger a conceptualization of ancestry that combined geography and history. Some participants suggested that the test-taker's all-European ancestry was due to an absence of migration among his ancestors. One participant, for instance, said, "I'm not really surprised it's all in the same continent cause ... transportation hasn't been great up until pretty recently in the scale of like, you know, human history" (Matthew). Others, conversely, attributed the test-taker's ancestry mix to the presence of regional migration. A participant who was looking at a combination of German and Norwegian ancestry groups, said:

Thinking about Germany and Norway being so close in this map, maybe those ancestors traveled from one place to the other, maybe because at the time it was easier, maybe ... when all the situations in World War II were happening, that was when they traveled to Norway or vice versa. (Katherine)

Only three participants suggested that the test-taker's ancestry mix resulted from genetic intermixing in the United States. One of these participants reasoned: "[This person is] mostly European and they probably ... just had ancestors that came to the U.S., probably during the Industrial Revolution, like, when ... the U.S. kind of became the U.S." (Olivia). 
When pressed to explain the meaning of ancestry, several participants did not provide a coherent answer, while others drew on a rudimentary conceptualization of ancestry as consisting of grandparents. A more geographically sophisticated group explained ancestry combinations in terms of migration. Nearly all participants answered these questions with considerable self-doubt.

\subsection{Scientific Explanation Confuses and Frustrates}

\subsubsection{Comprehension Difficulties}

Most participants had difficulty paraphrasing and interpreting the test's scientific explanation. Some were up-front about the explanation being too complicated to paraphrase: "Um, that ... I honestly don't know. That they're able to just match you with ... this is so complicated ... I don't know" (Mary). Other participants offered a paraphrase but their reasoning demonstrated misunderstandings:

If I was understanding it right, they were saying that $50 \%$ of your DNA matches other people ... I got, like, how they calculated it, because it says they determine it by, like ... they track it by basically spanning across the globe, and tracking your DNA, and going across the globe. But I didn't get, like, how they get your DNA, which is kind of what I was looking for, and that's what got kind of confusing for me. (Stephanie)

Almost universally, the scientific explanation proved too challenging for participants to interpret accurately.

\subsubsection{Doubting the Results}

The scientific explanation for several participants introduced doubt about result reliability. All of these participants had either first- or second-hand experience with an ancestry test. Two participants wondered how the results' accuracy is affected by one's DNA being matched to DNAs that closely rather than fully resemble it. Another two participants noted that the results were likely to change as more individuals' DNA was added to the reference database. A number of participants underscored that the results were estimated at a 50\% confidence level: "Something that was surprising to me was where they said, 'By default, your results are calculated at $50 \%$ confidence level.' That seems, you know, while substantial, it seems kind of small to determine somebody's ancestry" (Elizabeth). Another participant built on her diminished trust in the results, and suggested that the DNA testing companies deceive their customers:

I feel like if you buy a toaster and 50\% [of the time] it would work and 50\% it won't, it's, like, why would I buy that toaster? It's not worth it if it's only going to make toasts every other day. That's just not a reliable company to me. (Laura)

While it's not known how often genetic test clients read the scientific explanation that accompanies their results, these interviews suggest that many who read the scientific explanation had a hard time understanding it. Some participants who understood elements of the explanation became skeptical of the test results.

\subsection{Legitimate Ancestry Identities}

\subsubsection{Personal Choice and Culture}

To understand how individuals understand legitimate identity vis-a-vis ancestry results, participants reflected on whether the test-taker could accurately identify with low-proportion ancestry groups listed in the results. Participants oscillated between a hands-off stance, suggesting that cultural practices legitimate identity, and determining various thresholds for accurately identifying with low-ancestry groups.

Some participants said that they would not argue against individuals identifying with low-ancestry groups: 
It is not my place to decide who someone believes they are, or what culture they want to believe in, or celebrate, or put forth their love for. Because I feel like if you appreciate it, then it's fine to identify with it to a certain extent. (Christina)

Others argued that cultural experience legitimizes identification with an ancestry group: "If they lived in Russia, I think they could be part of that culture and how they experience life. So I think... it wouldn't be fair for me to say that they aren't Russian" (Allison). On the flip side, some participants argued that the lack of experience with a culture delegitimizes one's claim to an ancestry, even if their genetics point to it:

I guess DNA can tell you maybe where your ancestry was located but if you've never learned what that means, or what that history is, or the traditions that are in that culture, and you don't really practice that, then that's not really who you are. (Andrea)

\subsubsection{Thresholds}

Several participants identified specific thresholds in ancestry group proportions that demarcate legitimate identities. Although there was no clear consensus and some participants said that even a $4.2 \%$ proportion was legitimate, several pointed to a range between 10 and $20 \%$ as the lowest valid ancestry-based identity. One participant identified both a $20 \%$ and a $10 \%$ threshold:

I feel like, if someone were to tell me that "I am French," and I say, "What percentage of French are you?" and they say a number under, like, 20\%, I would say, "Oh. You are not really French." I feel like anything under 10\% might be stretching it. You are not really that. (Andrea)

Another participant pointed to an approximate $10 \%$ threshold:

I feel like it is mainly based on what the person wants to interpret their result as. But if we are going to go numerical, I'd say at least $10 \%$ of something in order to say, "Yes, I am definitely this." (Christina)

Another participant, asked to identify a threshold at which someone would be legitimately a certain identity, pointed to the "Norwegian, 16.6\%" group in her results: "Probably around the Norwegian one, the 16.6, so around 15" (Mary).

There was no consensus on what constitutes legitimate ancestry-based identity, with some participants declining to adjudicate the issue, others arguing that cultural experience is necessary to legitimize identity, and others identifying a range of thresholds around 10 to $20 \%$.

\section{Discussion}

For the first time since the introduction of genetic testing, direct-to-consumer genetic tests allow members of the general public to interpret test results without professional guidance. Genetic ancestry tests are increasingly omnipresent in U.S. culture. News outlets regularly publish reports about individuals being shocked by their ancestry test results (e.g., Marcus 2019; Sheridan 2019). As of summer $2019,15 \%$ of U.S. adults had taken a genetic ancestry test, most with the goal of finding where their ancestors came from (Graf 2019). Given their increasing ubiquity, genetic ancestry tests are bound to spark future public controversies. This study set out to identify how individuals interpret ancestry test results and what informs these interpretations, to better understand how the public might make sense of newsworthy ancestry test results in the future. Despite the recent popularity of genetic ancestry tests, findings suggest a general lack of understanding about how these results are derived and how to interpret them.

The study's overall conclusions about how individuals interpret ancestry test results consist of two parts, which parallel the bottom-up and top-down interpretation processes. When interpreting the meaning of ancestry groups and the associated percentages and regions, participants' interpretations were informed by the stimulus, indicating bottom-up processing. When probed further on what it 
means to belong to an ancestry group, participants drew on their existing knowledge of genetics, family, and experience with ancestry tests, suggesting top-down processing. Participants felt confident in their bottom-up reading of the results. Conversely, their reasoning revealed cognitive gaps and misunderstanding when they articulated top-down interpretations. Combined, these conclusions point to an illusion of knowing what genetics, ancestry tests, and their results mean (Lanie et al. 2004; Park 2001; Pearson and Liu-Thompkins 2012).

The illusion of knowing refers to a disparity between what individuals think they know about a subject and what they objectively know about it. Research has documented the illusion of knowing in domains such as climate change (Yang et al. 2020) and politics (Park 2001). The fluency of the information that presents a subject, that is, how easy it is to understand it, improves individuals' confidence that they understand that subject (Glenberg et al. 1982). Information fluency can contribute to the illusion of knowing if individuals' perceived knowledge on the subject is higher than their objective knowledge (Ryffel and Wirth 2020). In addition to supporting the fluency of the results, the map also may have contributed to how credible they appeared. An image or photograph can enhance the credibility assessments of a thematically related message, even when the image doesn't provide any evidence of the claim made in the message (Newman et al. 2020).

The fluency of the results our participants viewed-how easy to interpret the results appeared to be-likely drove their illusion that they understood the ancestry test and what its results conveyed. The combination of the result elements-ancestry groups, percentages, and color-coded map-appeared to reinforce the results' fluency, that is, their intuitive nature. This fluency also appeared to override several participants' reservations about their map-reading abilities. Participants who voiced apprehension about reading a map in general found that this particular map's color-coding helped them read and interpret the results. The intuitive appearance of the map also limited the critical thinking we may have expected some participants to apply to the stimulus. None of the participants, including those who scored high on the map-reading test and those who reflected on migration in their interpretations of the results, noted that the map they viewed showed present-day borders, not historical ones. While pairing ancestry groups with a present-day map may make intuitive sense, it does not reflect the complex histories of many ethnicities, nationalities, and regions.

The fluency our participants attributed to the results did not inform their actual understanding of ancestry tests. The uncertainty about the scientific meaning of the results, which many of our participants expressed, pointed to their low objective understanding of the results. Interviewers' probing about the meaning of the ancestry groups, their percentages, and the results' scientific explanation, elicited some direct admissions of not understanding these elements. Participants' allusions to grandparents and migration, and their reliance on their own experiences with ancestry test results hinted at deficiencies in their genetic literacies. Grandparents represent the closest living link to ancestors for many individuals, which may explain why some participants reached for this concept. For others, the map prompted the idea of migration as a contributor to the intermingling of ancestry groups. Both of these concepts, and the tendency to interpret the results based on direct or indirect previous experience with genetic ancestry tests, served to patch over participants' uncertainties about the results' objective meaning.

This paper opened with the story of Elizabeth Warren's ancestry test results. What are the implications of the study's findings - that individuals believe they understand ancestry test results, while displaying major deficiencies in interpreting their meaning-for understanding public reactions to news-makers' genetic ancestry tests results? The study illustrates what prior research has found: that, while the public may be increasingly familiar with basic genetic terminology, its understanding of the science of genetics remains low (Haga et al. 2013; Lanie et al. 2004). The fluent nature of genetic ancestry results may intensify individuals' perception that they understand genetics and what ancestry results mean. The illusion of knowing a subject, however, can demotivate further learning and encourage misguided attitudes (Park 2001). All this suggests that the next time someone's ancestry 
results make the news, individuals will project onto these results the interpretations that best fit their preconceptions, regardless of how much they understand the science of genetic ancestry tests.

Critics of genetic ancestry testing argue that testing companies fail to explain that results are not the only source of information about family and ethnic identity (Nordgren and Juengst 2009). This study's participants, however, indicated that the test results help legitimize identity. While participants agree that test result numbers do not fully determine one's identity, they also agree that the results help validate previously conceived identities. There was no consensus on exact percentage thresholds for identity validation, with many participants expressing a "who am I to judge" attitude and a wariness to provide an exact number. When probed further, some participants, like those in previous research (Shim et al. 2018), suggested that smaller percentage thresholds, combined with lived experience as members of a particular identity group, validate one's identity. Other participants were less accepting of smaller percentage numbers as proof of identity legitimization. Overall, this study suggests that the public's reaction to Elizabeth Warren's highly publicized ancestry results may have been more bifurcated than the broad condemnation of her claim to Native American ancestry that dominated the media narrative following the release of her test results.

This study's limitations suggest directions for future research. The study's sample primarily consisted of female college students, suggesting the need for other segments of the population who may have divergent opinions about genetic ancestry tests to be represented in future studies. Future qualitative work may probe the co-production of meaning in which test-takers and others who interpret ancestry test results engage. From the perspective of quantitative research methods, this study's small sample size limited the utility of its map literacy evaluation. Although there were no differences in participants' responses based on map literacy scores, such differences may emerge in quantitative research with larger sample sizes and other literacy evaluations. The use of a present-day map that does not reflect the historical circumstances of the ancestors whom the test purports to represent also may be more critically examined in future work. The exploratory nature of this study also calls for future studies to systematically and independently measure the relationships between variables like literacy levels and exposure to advertisements that may impact perceptions of knowledge and overall result interpretations. Future research also may explore the fluency of results as a function of layout designs of greater and lesser complexity, which may illustrate nuances in interpretations.

Overall, this study's results bode well for the profits of genetic ancestry testing companies, but not for the general population's genetic literacy. Testing companies benefit from consumers' illusion that ancestry tests and their results are intuitive and easy to understand. Marketing research shows that subjective knowledge - the perception that one understands a product or category-drives purchasing more than objective knowledge (Aertsens et al. 2011). To sustain consumers' interest in purchasing ancestry tests, testing companies are likely to continue to affirm the fluency with which consumers view genetic ancestry tests, and to minimize objective information about how the tests work and what their results mean. Aggressive advertising campaigns, moreover, likely lead test-takers to overestimate how much genetic ancestry tests can define and confirm identity (Nordgren and Juengst 2009; Roth and Ivemark 2018; Scodari 2017). AncestryDNA and 23andMe ads have positioned the test as a way to uncover personal identities with slogans like "Learn You" and "Reinventing Ancestry," and with imagery of people changing their traditions and clothing in response to their test results (Scodari 2017). 23andMe also has claimed that DNA can help individuals increase their self-knowledge (Nordgren and Juengst 2009). By matching patterns of genetic variation between current and prior test-takers, however, genetic ancestry tests only reveal clues about where a person's DNA might have come from (Royal et al. 2010). Our results reinforce arguments that individuals continue to misunderstand genetics as a determining factor of who they are and what they are like (Royal et al. 2010; Rutherford 2018). Consumers' overestimations and misunderstandings benefit the testing companies, driving the public's interest in and sales of genetic ancestry results at the expense of test-takers' genetic literacy. 
Author Contributions: Conceptualization, P.S.B., J.C.W. and O.O.A.; methodology, P.S.B., J.C.W. and O.O.A.; analysis, P.S.B., J.C.W. and O.O.A.; writing-original draft preparation, P.S.B., J.C.W. and O.O.A.; writing-review and editing, P.S.B. All authors have read and agreed to the published version of the manuscript.

Funding: This research received no external funding.

Acknowledgments: The authors express their gratitude to Jennifer Raff and Justin Tackney of the Ancient DNA Laboratory, University of Kansas, for supporting this project's outset and offering helpful comments on the article's drafts.

Conflicts of Interest: The authors declare no conflict of interest.

\section{Appendix A. Interview Question Protocol}

Follow-up questions to ask after the participant's initial interpretations:

1. How difficult or easy was it to interpret these results?

2. Have you taken a test like this before?

a. What did you learn from your results?

b. What do your test results mean to you?

3. What does the right section of the results tell us? What does the left section tell us?

4. Depending on the answer, ask a follow-up to get closer to what the numbers really mean. Ex. What does it mean to be $4 \%$ Welsh?

5. Thinking specifically about the list of countries (or regions), how difficult or easy was it to interpret these results?

6. What do these results say about this person's ancestry? (Probe as necessary)

a. What continents are most of this person's ancestors from?

b. What continents are the ancestors not from?

7. Were you surprised by these results? Why or why not?

8. So, if this person came to you and said, "You know what, I'm " And then they gave you these results, would you think that's an accurate representation of their identity? (fill in the blank with points below)

a. Ask about the largest and the smallest percentages (excluding unassigned)

b. One country between $4 \%-5 \%$ (excluding unassigned)

c. For the stimuli with only 4 countries just ask about the largest and smallest percentage (excluding unassigned)

9. At what point or what percentage would you consider this person to be ? (the lowest \% on the stimulus)

10. What does the unassigned ancestry label mean?

11. Do you trust these results? Why or why not?

Thank you, now I will show you the instructions on how to interpret these results. When you are done reading, I'll ask you to interpret the results again.

12. What do these instructions mean?

13. Would you consider purchasing an ancestry DNA test? Why or why not?

\section{References}

23andMe. 2019. Ancestry Composition: 23andMe's State-of-the-Art Geographic Ancestry Analysis. Available online: https://www.23andme.com/ancestry-composition-guide/ (accessed on 15 December 2019). 
Aertsens, Joris, Koen Mondelaers, Wim Verbeke, Jeroen Buysse, and Guido Van Huylenbroeck. 2011. The influence of subjective and objective knowledge on attitude, motivations and consumption of organic food. British Food Journal 113: 1353-78. [CrossRef]

Agurs-Collins, Tanya, Rebecca Ferrer, Allison Ottenbacher, Erika A. Waters, Mary E. O'Connell, and Jada G. Hamilton. 2015. Public awareness of direct-to-consumer genetic tests: Findings from the 2013 US Health Information National Trends Survey. Journal of Cancer Education 30: 799-807. [CrossRef] [PubMed]

Bolnick, Deborah A., Duana Fullwiley, Troy Duster, Richard S. Cooper, Joan H. Fujimura, Jonathan Kahn, Jay S. Kaufman, Jonathan Marks, Ann Morning, Alondra Nelson, and et al. 2007. The science and business of genetic ancestry testing. Science 318: 399-400. [CrossRef] [PubMed]

Borry, Pascal, Mahsa Shabani, and Heidi C. Howard. 2013. Nonpropositional content in direct-to-consumer genetic testing advertisements. The American Journal of Bioethics 13: 14-16. [CrossRef] [PubMed]

Braun, Virginia, and Victoria Clarke. 2006. Using thematic analysis in psychology. Qualitative Research in Psychology 3: 77-101. [CrossRef]

Braun, Virginia, and Victoria Clarke. 2012. Thematic analysis. In APA Handbook of Research Methods in Psychology. Edited by Harris Cooper. Washington, DC: American Psychological Association, vol. 2, pp. 57-71.

Brodwin, Paul. 2002. Genetics, identity, and the anthropology of essentialism. Anthropological Quarterly 75: 323-30. [CrossRef]

Brubaker, Rogers. 2016. The Dolezal affair: Race, gender, and the micropolitics of identity. Ethnic and Racial Studies 39: 414-48. [CrossRef]

Bucher, Hans-Jürgen, and Peter Schumacher. 2006. The relevance of attention for selecting news content: An eye-tracking study on attention patterns in the reception of print and online media. Communications 31: 347-68. [CrossRef]

Casali, John G., and Kenneth B. Gaylin. 1988. Selected graph design variables in four interpretation tasks: A microcomputer-based pilot study. Behaviour \& Information Technology 7: 31-49.

Christensen, Kurt D., Toby E. Jayaratne, Scott Roberts, Sharron L. R. Kardia, and Elizabeth M. Petty. 2010. Understandings of basic genetics in the United States: Results from a national survey of black and white men and women. Public Health Genomics 13: 467-76. [CrossRef]

Council on Foreign Relations and National Geographic. 2016. What College-Aged Students Know about the World: A Survey on Global Literacy. New York: Council on Foreign Relations, September, Available online: https://www.cfr.org/content/newsletter/files/CFR_NatGeo_ASurveyonGlobalLiteracy.pdf (accessed on 23 February 2019).

Cross, John A. 1987. Factors associated with students' place location knowledge. Journal of Geography 86: 59-63. [CrossRef]

Downs, Julie S., Wändi Bruine de Bruin, and Baruch Fischhoff. 2008. Parents' vaccination comprehension and decisions. Vaccine 26: 1595-607. [CrossRef] [PubMed]

Dunlop, Charles E. M., and James H. Fetzer. 1993. Glossary of Cognitive Science. New York: Paragon House.

Felzmann, Heike. 2015. 'Just a bit of fun': How recreational is direct-to-consumer genetic testing? The New Bioethics 21: 20-32. [CrossRef] [PubMed]

Foeman, Anita, Bessie Lee Lawton, and Randall Rieger. 2015. Questioning race: Ancestry DNA and dialog on race. Communication Monographs 82: 271-90. [CrossRef]

Gabel, Jessica D. 2012. Redeeming the genetic Groupon: Efficacy, ethics, and exploitation in marketing DNA to the masses. Mississippi Law Journal 81: 363-438.

Glenberg, Arthur M., Alex Cherry Wilkinson, and William Epstein. 1982. The illusion of knowing: Failure in the self-assessment of comprehension. Memory \& Cognition 10: 597-602.

Graf, Nikki. 2019. Mail-in DNA Test Results Bring Surprises about Family History for Many Users. Pew Research Center. August 6. Available online: https://www.pewresearch.org/fact-tank/2019/08/06/mail-in-dna-testresults-bring-surprises-about-family-history-for-many-users/ (accessed on 7 February 2020).

Haga, Susanne B., William T. Barry, Rachel Mills, Geoffrey S. Ginsburg, Laura Svetkey, Jennifer Sullivan, and Huntington F. Willard. 2013. Public knowledge of and attitudes toward genetics and genetic testing. Genetic Testing and Molecular Biomarkers 17: 327-35. [CrossRef]

Horowitz, Adam L., Aliya Saperstein, Jasmine Little, Martin Maiers, and Jill A. Hollenbach. 2019. Consumer (dis-)interest in genetic ancestry testing: The roles of race, immigration, and ancestral certainty. New Genetics and Society 38: 165-94. [CrossRef] 
Jobling, Mark A., Rita Rasteiro, and Jon H. Wetton. 2016. In the blood: The myth and reality of genetic markers of identity. Ethnic and Racial Studies 39: 142-61. [CrossRef]

Juengst, Eric T. 2004a. DNA identification. In Encyclopedia of Bioethics, 3rd ed. Edited by Stephen G. Post. New York: Macmillan Reference, pp. 677-83.

Juengst, Eric T. 2004b. Genetic testing and screening: Population screening. In Encyclopedia of Bioethics, 3rd ed. Edited by Stephen G. Post. New York: Macmillan Reference, pp. 1007-16.

Kruikemeier, Sanne, Sophie Lecheler, and Ming M. Boyer. 2018. Learning from news on different media platforms: An eye-tracking experiment. Political Communication 35: 75-96. [CrossRef]

Lanie, Angela D., Toby Epstein Jayaratne, Jane P. Sheldon, Sharon L. R. Kardia, Elizabeth S. Anderson, Merle Feldbaum, and Elizabeth M. Petty. 2004. Exploring the public understanding of basic genetic concepts. Journal of Genetic Counseling 13: 305-20. [CrossRef] [PubMed]

Lee, Sandra Soo-Jin. 2013. Race, risk, and recreation in personal genomics: The limits of play. Medical Anthropology Quarterly 27: 550-69. [CrossRef] [PubMed]

Lewandowsky, Stephan, and John T. Behrens. 1999. Statistical graphs and maps. In Handbook of Applied Cognition. Edited by Francis T. Durso, Raymond S. Nickerson, Roger W. Schvaneveldt, Susan T. Dumais, D. Stephen Lindsay and Michelene T. H. Chi. New York: John Wiley \& Sons, pp. 514-49.

Lewis, Norman P., Debbie Treise, Stephen I. Hsu, William L. Allen, and Hannah Kang. 2011. DTC genetic testing companies fail transparency prescriptions. New Genetics and Society 30: 291-307. [CrossRef]

Linskey, Annie. 2018. Elizabeth Warren Releases Results of DNA Test. Boston Globe. October 15. Available online: https://www.bostonglobe.com/news/politics/2018/10/15/warren-addresses-native-american-issue/ YEUaGzsefB0gPBe2AbmSVO/story.html (accessed on 7 February 2020).

Lorenzoni, Irene, and Nick F. Pidgeon. 2006. Public views on climate change: European and USA perspectives. Climatic Change 77: 73-95. [CrossRef]

Marcus, Amy D. 2019. A white woman searches for her black family: A home DNA test led Christine Jacobsen to grapple with complicated questions about her racial identity. The Wall Street Journal. November 21. Available online: https://www.wsj.com/articles/a-white-woman-searches-for-her-black-family-1157262511 (accessed on 7 February 2020).

Meyer, Joachim, David Shinar, and David Leiser. 1997. Multiple factors that determine the performance with tables and graphs. Human Factors 39: 268-86. [CrossRef]

Miller, Jon D. 2004. Public understanding of, and attitudes toward, scientific research: What we know and what we need to know. Public Understanding of Science 13: 273-94. [CrossRef]

Molster, Charles T., Amanda Samanek, and Peter O'Leary. 2009. Australian study on public knowledge of human genetics and health. Public Health Genomics 12: 84-91. [CrossRef]

National Science Board (NSB). 2018. Chapter 7: Science and Technology—Public Attitudes and Public Understanding. Science and Engineering Indicators. Available online: https:/www.nsf.gov/statistics/2018/nsb20181/report/ sections/science-and-technology-public-attitudes-and-understanding/public-knowledge-about-s-t (accessed on 10 February 2020).

Nelson, Alondra, and Jeong Won Hwang. 2013. Roots and revelation: Genetic ancestry testing and the youtube generation. In Race after the Internet. New York: Routledge, pp. 277-96.

Nelson, Alondra. 2008. Bio science: Genetic genealogy testing and the pursuit of African ancestry. Social Studies of Science 38: 759-83. [CrossRef]

Newman, Eryn J., Madeline C. Jalbert, Norbert Schwarz, and Deva P. Ly. 2020. Truthiness, the illusory truth effect, and the role of need for cognition. Consciousness and Cognition 78: 1-16. [CrossRef]

Nordgren, Anders, and Eric T. Juengst. 2009. Can genomics tell me who I am? Essentialistic rhetoric in direct-to-consumer DNA testing. New Genetics and Society 28: 157-72. [CrossRef]

Norman, Donald A., and David E. Rumelhart. 1975. Explorations in Cognition. San Francisco: W. H. Freeman and Company.

O'reilly, Michelle, and Nicola Parker. 2013. 'Unsatisfactory Saturation': A critical exploration of the notion of saturated sample sizes in qualitative research. Qualitative Research 13: 190-97. [CrossRef]

Ostergren, Jenny E., Michele C. Gornick, Deanna Alexis Carere, Sarah S. Kalia, Wendy R. Uhlmann, Mack T. Ruffin, Joanna L. Mountain, Robert C. Green, J. Scott Roberts, and PGen Study Group. 2015. How well do customers of direct-to-consumer personal genomic testing services comprehend genetic test results? Findings from the impact of personal genomics study. Public Health Genomics 18: 216-24. [CrossRef] [PubMed] 
Panofsky, Aaron, and Joan Donovan. 2019. Genetic ancestry testing among white nationalists: From identity repair to citizen science. Social Studies of Science 49: 653-81. [CrossRef] [PubMed]

Park, Cheong-Yi. 2001. News media exposure and self-perceived knowledge: The illusion of knowing. International Journal of Public Opinion Research 13: 419-25. [CrossRef]

Pearson, Yvette E., and Yuping Liu-Thompkins. 2012. Consuming direct-to-consumer genetic tests: The role of genetic literacy and knowledge calibration. Journal of Public Policy E Marketing 31: 42-57.

Pieters, Rik, and Michel Wedel. 2007. Goal control of attention to advertising: The Yarbus implication. Journal of Consumer Research 34: 224-33. [CrossRef]

Post Editorial Board. 2018. Warren still Has to Answer for Her Ethnic Identity Theft. New York Post. October 16. Available online: https://nypost.com/2018/10/16/warren-still-has-to-answer-for-her-ethnic-identity-theft/ (accessed on 7 February 2020).

Quaid, Kimberly A. 2004. Genetic testing and screening: Predictive genetic testing. In Encyclopedia of Bioethics, 3rd ed. Edited by Stephen G. Post. New York: Macmillan Reference, pp. 1020-25.

Regalado, Antonio. 2019. More than 26 Million People Have Taken an At-Home Ancestry Test. MIT Technology Review. February 11. Available online: https://www.technologyreview.com/s/612880/more-than-26-millionpeople-have-taken-an-at-home-ancestry-test/ (accessed on 7 February 2020).

Roth, Wendy D., and Biorn Ivemark. 2018. Genetic options: The impact of genetic ancestry testing on consumers' racial and ethnic identities. American Journal of Sociology 124: 150-84. [CrossRef]

Royal, Charmaine D., John Novembre, Stephanie M. Fullerton, David B. Goldstein, Jeffrey C. Long, Michael J. Bamshad, and Andrew G. Clark. 2010. Inferring genetic ancestry: Opportunities, challenges, and implications. The American Journal of Human Genetics 86: 661-73. [CrossRef]

Rubin, Herbert J., and Irene S. Rubin. 2012. Qualitative Interviewing: The Art of Hearing Data, 3rd ed. Thousand Oaks: SAGE.

Rutherford, Adam. 2018. A Brief History of Everyone Who Ever Lived: The Human Story Retold Through our Genes. New York: The Experiment.

Ryffel, Fabian A., and Werner Wirth. 2020. How perceived processing fluency influences the illusion of knowing in learning from TV reports. Journal of Media Psychology 32: 2-13. [CrossRef]

Schleckser, Kathryn. 2013. Physician participation in direct-to-consumer genetic testing: Pragmatism or paternalism. Harvard Journal of Law \& Technology 26: 695-730.

Scodari, Christine. 2017. When markers meet marketing: Ethnicity, race, hybridity, and kinship in genetic genealogy television advertising. Genealogy 1: 22. [CrossRef]

Scully, Marc, Steven D. Brown, and Turi King. 2016. Becoming a Viking: DNA testing, genetic ancestry and placeholder identity. Ethnic and Racial Studies 39: 162-80. [CrossRef]

Shah, Jatin Y., Amruta Phadtare, Dimple Rajgor, Meenakshi Vaghasia, Shreyasee Pradhan, Hilary Zelko, and Ricardo Pietrobon. 2010. What leads Indians to participate in clinical trials? A meta-analysis of qualitative studies. PLoS ONE 5: e10730. [CrossRef]

Shah, Priti, and Eric G. Freedman. 2011. Bar and line graph comprehension: An interaction of top-down and bottom-up processes. Topics in Cognitive Science 3: 560-78. [CrossRef]

Shah, Priti, Eric G. Freedman, and Ioanna Vekiri. 2005. The comprehension of quantitative information in graphical displays. In The Cambridge Handbook of Visuospatial Thinking. Edited by Priti Shah and Akira Miyake. New York: Cambridge University Press, pp. 426-76.

Shah, Priti, Richard E. Mayer, and Mary Hegarty. 1999. Graphs as aids to knowledge construction: Signaling techniques for guiding the process of graph comprehension. Journal of Educational Psychology 91: 690-702. [CrossRef]

Sheridan, Wade. 2019. WWE's Seth Rollins Discovers He Has Siblings with DNA Test. United Press International. September 11. Available online: https://www.upi.com/Entertainment_News/2019/09/11/WWEs-Seth-Rollinsdiscovers-he-has-siblings-with-DNA-test/4401568218638/ (accessed on 7 February 2020).

Shim, Janet K., Sonia Rab Alam, and Bradley E. Aouizerat. 2018. Knowing something versus feeling different: The effects and non-effects of genetic ancestry on racial identity. New Genetics and Society 37: 44-66. [CrossRef]

Silk, Kami J., and Roxanne L. Parrott. 2014. Math anxiety and exposure to statistics in messages about genetically modified foods: Effects of numeracy, math self-efficacy, and form of presentation. Journal of Health Communication 19: 838-52. [CrossRef] 
Stephens, Maria, Laura K. Warren, Ariana L. Harner, and Eugen Owen. 2015. Comparative Indicators of Education in the United States and Other G20 Countries: 2015. In National Center for Education Statistics. Available online: https://nces.ed.gov/pubs2016/2016100.pdf (accessed on 7 February 2020).

Vayena, Effy, Christian Ineichen, Elia Stoupka, and Ernst Hafen. 2014. Playing a part in research? University students' attitudes to direct-to-consumer genomics. Public Health Genomics 17: 158-68. [CrossRef]

Wade, Peter. 2019. Elizabeth Warren Apologized to Cherokee Nation for DNA Test: The Senator Hopes It Will Put This Issue to Bed. Rolling Stone. February 2. Available online: https://www.rollingstone.com/politics/politicsnews/warren-dna-test-apology-789180/ (accessed on 7 February 2020).

Wagner, Jennifer K., and Kenneth M. Weiss. 2012. Attitudes on DNA ancestry tests. Human Genetics 131: 41-56. [CrossRef]

Weise, Elizabeth. 2018. These Are the Top Companies Offering Genealogical DNA Testing to Learn about Your Family. USA Today. December 2. Available online: https://www.usatoday.com/story/news/2018/12/02/ genealogical-dna-testing-companies-ancestry-23-andme/2141344002/ (accessed on 20 April 2020).

Winship, Jodi M. 2004. Geographic Literacy and World Knowledge among Undergraduate College Students. Unpublished Master's thesis, Virginia Polytechnic Institute and State University, Blacksburg, VA, USA. Available online: https://vtechworks.lib.vt.edu/bitstream/handle/10919/10177/Final_Thesis_JWinship.pdf (accessed on 7 February 2020).

Yang, Xiaodong, Liang Chen, and Shirley S. Ho. 2020. Does media exposure relate to the illusion of knowing in the public understanding of climate change? Public Understanding of Science 29: 94-111. [CrossRef]

Zhou, Li. 2019. Poll: Elizabeth Warren's Handling of Her DNA Results Hurts Her Favorability—But Not Her Electoral Chances. Vox. May 8. Available online: https:/www.vox.com/2019/5/8/18535741/poll-elizabethwarren-dna-test-2020-democratic-primary (accessed on 7 February 2020).

(C) 2020 by the authors. Licensee MDPI, Basel, Switzerland. This article is an open access article distributed under the terms and conditions of the Creative Commons Attribution (CC BY) license (http://creativecommons.org/licenses/by/4.0/). 